\title{
A EXCLUSÃO DIGITAL E A CIDADANIA PARTICIPATIVA NA SOCIEDADE EM REDE
}

\author{
DIGITAL DIVIDE AND PARTICIPATORY \\ CITIZENSHIP IN THE NETWORK SOCIETY
}

\author{
ANDRÉ AFONSO TAVARES ${ }^{1}$ \\ REGINALDO DE SOUZA VIEIRA ${ }^{2}$
}

\section{RESUMO}

A sociedade se transforma cada vez com mais intensidade a partir das inovações trazidas pelo uso de novas tecnologias, que implicam no repensar as formas de agir, interagir e informar e transformar o modo como se vive em escala local, regional, nacional e mundial. A partir da formatação dessa realidade, a qual Castells denomina sociedade em rede, há que se refletir acerca de uma nova forma de exclusão social a ela inerente, isto é, a exclusão digital ou, no termo mais conhecido em inglês, digital divide. Dessa forma, o presente trabalho girou em torno da seguinte problemática: de que forma a exclusão digital está relacionada com o exercício da cidadania participativa, sobretudo no âmbito eletrônico, na sociedade em rede? Para a realização da pesquisa, adotou-se o método dedutivo, a partir da técnica de pesquisa bibliográfica e documentação indireta. A partir da pesquisa realizada, foi possível concluir que os aspectos que envolvem a exclusão digital vão além do mero acesso à internet ou aos tradicionais mecanismos eletrônicos, tais como computador ou celular, visto que eles abarcam diversos fatores de ordem técnica, social e geográfica. Nesse sentido, superar a exclusão digital por meio da ampliação e criação de políticas públicas que combatam as desigualdades sociais e as limitações técnicas, geracionais, étnicas, culturais, sociais e geográficas, bem como a partir do desenvolvimento de ferramentas eletrônicas de cidadania, é fundamental para o aumento da utilização da cidadania digital como instrumento para o fortalecimento da participação política, em especial, no âmbito da cidadania participativa.

Palavras-chave: Cidadania participativa. Cidadania eletrônica. Exclusão digital. Internet. Sociedade em rede.

1 Mestrando do Programa de Pós-Graduação/Mestrado em Direito da UNESC. Membro do Núcleo de Estudos em Estado, Política e Direito (NUPED/UNESC) Especialista em Direito Público e em Auditoria Governamental. Graduado em Direito e em Ciências Contábeis. Graduando em Engenharia de Software. Advogado. Contador. ORCID iD: https://orcid.org/0000-00029549-8096. E-mail: afonsotavares.andre@gmail.com.

2 Doutor (2013) e Mestre (2002) em Direito pelo Programa de Pós-graduação em Direito - Mestrado e Doutorado, da Universidade Federal de Santa Catarina. Professor, pesquisador e Coordenador Adjunto do Programa de Pós-Graduação em Direito (PPGD/UNESC). Professor e pesquisador do Programa de Pós-Graduação em Desenvolvimento Socioeconômico (PPGDS/UNESC). Professor titular da Universidade do Extremo Sul Catarinense. Coordenador do Núcleo de Estudos em Estado, Política e Direito (NUPED/UNESC) e do Laboratório de Direito Sanitário e Saúde Coletiva (LADSSC/UNESC). Membro da Rede Ibero-americana de Direito Sanitário. Membro e Coordenador da Rede Brasileira de Pesquisa Jurídica em Direitos Humanos. ORCID iD: http://orcid.org/0000-0001-6733-5321. E-mail: prof.reginaldovieira@gmail.com. 


\section{ABSTRACT}

Society is changing more and more with the innovations brought by new technologies, implying the rethinking of ways people act, interact, inform and transform the way they live on a local, regional, national, and global scale. Based on this reality, which Castells describes as a network society, it is essential to reflect on the new form of social exclusion inherent to it, that is, the digital divide. This paper's investigation problem revolves around how is the digital divide related to the exercise of participatory citizenship, especially in the electronic sphere, in the networked society. The deductive method was used in this investigation based on the technique of bibliographic research and indirect documentation. Throughout the investigation, it was possible to conclude that the aspects that involve the digital divide go beyond internet access or the matter of having computers or cell phones since this issue combines several technical, social, and geographical aspects. In this sense, overcoming the digital divide is fundamental for the use of digital citizenship as an instrument to strengthen political participation, especially in the scope of participatory citizenship. That may be possible through the expansion and creation of public policies to subvert social inequalities and technical, generational, ethnic, cultural, social, and geographical limitations, and also the development of electronic citizenship tools.

Keywords: Participatory citizenship. Electronic citizenship. Digital divide. Internet. Network society.

\section{INTRODUÇÃO}

A sociedade se transforma cada vez com mais intensidade a partir das inovações trazidas pelo uso de novas tecnologias, de modo a possibilitar diferentes formas de pensar, agir, interagir e informar, bem como transformar a maneira como se vive e convive em escala local, regional, nacional e mundial.

Essas mudanças rompem com modelos paradigmáticos anteriores, exigindo do Estado e da sociedade a incorporação da complexidade (MORIN, 2011) a qual permeia o tecido social e que, em razão do projeto (CAPELLA, 2002) ou mito (GROSSI, 2007) da modernidade burguesa, foi desconsiderada, com vistas a permitir uma reprodução mais ampla e eficiente do modelo econômico capitalista (VIEIRA, 2013).

Nesse contexto, a era da informação, que emergiu para além do período industrial, incorpora esses elementos de complexidade e também de uma velocidade de dados que não foram conhecidos em nenhum outro momento da história da humanidade, ultrapassando as barreiras e as fronteiras da soberania estatal tradicionais.

Desse modo, estamos vivenciando um contexto em que paradigmas diferentes coabitam a mesma realidade social (KUHN, 1997; MORIN, 2011; PILATI, 2012), e esse é um desafio que o Direito e outros ramos do conhecimento precisam enfrentar.

Contudo, a partir da formatação dessa nova sociedade, a qual Castells (2005) denomina sociedade em rede, há que se refletir acerca do surgimento de uma forma de exclusão social a ela inerente, isto é, a exclusão digital, ou, no seu termo mais conhecido em inglês, digital divide, e não somente apenas do ponto de vista de acesso imediato aos serviços de internet ou aparelhos eletrônicos, como computador ou celular, mas também ao desfrute e manuseio desses meios para gerar comunicação, participação e interatividade, em especial no contexto da cidadania. 
Cidadania aqui compreendida como participativa, que reconheceu um novo paradigma advindo da República Participativa instituída pela Constituição da República Federativa do Brasil de 1988, a qual incorporou os elementos da complexidade, da diversidade, da multiculturalidade/interculturalidade. Esse novo marco da cidadania no texto constitucional não nega os pressupostos da cidadania representada, mas coexiste com eles de forma a se complementarem nos termos do Estado Social e Democrático de Direito (VIEIRA, 2013).

Dessa forma, o presente trabalho buscará refletir acerca da problemática referente à exclusão digital e ao seu impacto para a cidadania participativa na era digital, considerando o uso de novas tecnologias e o novo formato da sociedade em rede.

Buscar-se-á, assim, elucidar com a pesquisa o seguinte questionamento: de que forma a exclusão digital está relacionada com o exercício da cidadania participativa, sobretudo no âmbito eletrônico, na sociedade em rede?

A partir do problema que conduz as reflexões desta pesquisa, norteou-se o estudo principalmente pela análise do uso das novas tecnologias para o exercício e a ampliação da cidadania participativa no âmbito da relação Estado e sociedade, sem demérito das iniciativas realizadas pela sociedade civil organizada e a iniciativa privada, com o intuito de romper as barreiras de acesso tecnológico e ampliação do uso de suas ferramentas.

No desenvolver do artigo, faz-se o uso do método de abordagem dedutivo, adotando o procedimento monográfico e as técnicas de pesquisa bibliográfica e documental indireta.

Como objetivo geral, será investigado de que forma a exclusão digital está relacionada com o exercício da cidadania eletrônica na sociedade em rede.

Em um primeiro momento, serão estudados os aspectos que envolvem a formação da sociedade em rede, em especial a partir do advento das tecnologias, dos computadores e da internet.

Após, serão investigados os conceitos e os elementos que envolvem a exclusão digital, também denominada digital divide em inglês. Por último, buscar-se-á realizar um detalhamento da definição de cidadania participativa na era digital e, assim, analisar a problemática envolvendo os impactos da exclusão digital para o seu exercício no contexto da sociedade em rede.

\section{A SOCIEDADE EM REDE E A EXCLUSÁO DIGITAL NO BRASIL}

As transformações advindas da tecnologia e, em especial, da invenção da internet revolucionaram a forma de viver em sociedade, agora denominada sociedade em rede.

A sociedade, antes desconectada e isolada, passou a viver de forma global e intercontectada por sistemas de redes, cuja compreensão buscar-se-á melhor explorar no tópico seguinte. 
Importante ressaltar, contudo, que a sociedade em rede, embora entrelace, direta ou indiretamente, todas as pessoas, não traz consigo a resolução por completo da exclusão social, mas sim mais lucidez à outra forma de exclusão, a digital.

A exclusão social traz consigo raízes mais profundas que devem ser analisadas de forma mais detalhada a fim de compreendê-las, enquanto a exclusão digital, oriunda da vida digital, embora entrelaçada com a social, possui características próprias que merecem detaIhamento específico.

\subsection{SURGIMENTO DOS COMPUTADORES, DA INTERNET E DA SOCIEDADE EM REDE}

A partir do advento da tecnologia da informação, a sociedade passou a ser gradualmente transformada em diversas áreas, tais como na comunicação, no transporte, na educação, na segurança, na moradia, na saúde, nos relacionamentos, na organização governamental, etc.

Castells (2005) defende que embora essas tecnologias já pudessem ser observadas anos antes da década de 1940, tais como na invenção do telefone por Bell, em 1876; do rádio por Marconi, em 1898; e da válvula a vácuo por De Forest, em 1906; foi na Segunda Guerra Mundial e no período seguinte, com a invenção do primeiro computador programável e do transistor, fonte da microeletrônica, o verdadeiro cerne da Revolução da Tecnologia da Informação no século XX e, ainda, somente a partir da década de 1970 que ocorreu, de fato, a ampla difusão das novas tecnologias da informação.

Além disso, outro importante evento histórico que merece destaque para o surgimento da chamada sociedade em rede foi, sem dúvida, a criação e o desenvolvimento da Internet.

A invenção da Internet é atribuída ao trabalho da Agência de Projetos de Pesquisa Avançada (ARPA) do Departamento de Defesa dos EUA, a partir de uma fusão singular de estratégia militar, grande cooperação científica, iniciativa tecnológica e inovação contracultural, que, após o lançamento do primeiro Sputnik, resolveu criar um sistema de comunicação invulnerável a ataques nucleares, o que pode ser visto como precedente para a chegada da Era da Informação em grande escala (CASTELLS, 2005).

A primeira rede de computadores foi chamada de ARPANET e entrou em funcionamento em primeiro de setembro de 1969, sendo que somente durante a década de 1980 foi que a rede das redes se formou. Inicialmente, foi chamada ARPA-INTERNET, depois ficou conhecida apenas como INTERNET, nome ainda sustentado pelo Departamento de Defesa dos EUA e operado pela National Science Foundation (CASTELLS, 2005).

Apenas em 1990, na Europa, em virtude de ainda haver dificuldades para o uso da Internet, da limitada capacidade de transmissão de gráficos, da difícil localização e dos contratempos no recebimento de informações, que, após pesquisa realizada por um grupo de pesquisadores chefiado por Tim Berners Lee e Robert Cailliau, no Centre Européen pour Recherche Nucleaire (CERN), em Genebra, foi desenvolvida a conhecida teia mundial World Wide Web (WWW), a qual organizou o teor dos sítios da Internet por informação e não por localização, oferecendo aos usuários um sistema fácil de pesquisa para procurar as informações desejadas, com a criação de um formato para os documentos em hipertexto ao qual deram o nome de linguagem de marcação de hipertexto (hypertext markup language - HTML), acrescido ao 
protocolo TCP-IP e, ainda, com configuração de um protocolo de transferência de hipertexto (hypertext transfer protocol - HTTP) e a criação de um formato padronizado de endereços, o localizador uniforme de recursos (uniform resource locator - URL) (CASTELLS, 2005).

A Era da Informação, portanto, pode ser considerada, de certa forma, recente, com precedentes que datam os anos de 1970, com a criação do sistema operacional para computadores, e de 1990, com o surgimento da rede www para acesso à internet, os quais revolucionaram a sociedade de forma ainda inimaginável.

É bem verdade que a tecnologia não tem o condão de determinar por si só os rumos de uma sociedade nem pode ditar os caminhos das transformações tecnológicas na medida em que muitos aspectos, desde a criatividade até a iniciativa empreendedora, influenciam nesse processo tecnológico-científico, de uma novação e aplicações sociais, sendo o resultado fruto de um complexo padrão interativo (CASTELLS, 2005).

Contudo, é inegável a complexidade existente no desenho do Estado moderno, com fatores que impedem a participação dos indivíduos na tomada de decisões, em razão da burocracia e hierarquia existente na sua estrutura administrativa. Além disso, a sociedade também resta cada vez mais complexa, a ponto de ser chamada de sociedade da informação ou do conhecimento, uma vez que a informação se revela como a força motriz das transformações e o combustível mais importante nos sistemas modernos de produção, bem como o intenso uso da tecnologia da informação em forma digital tem gerado a superação das estruturas administrativas hierarquizadas e verticalizadas em direção a relações de poder horizontalizadas, o que se cunhou de sociedade em rede (ROVER, 2009).

Dessa forma, o surgimento das tecnologias da informação seguramente influenciou nesta nova formatação social, chamada agora de sociedade em rede. Nome que se justifica a partir da noção de que as redes constituem a nova morfologia social de nossas sociedades, e a difusão da lógica de redes transforma substancialmente a operação e os resultados dos processos produtivos e de experiência, poder e cultura, sendo que, embora a forma de organização social em redes tenha existido em outros tempos e espaços, está-se diante de um novo paradigma oriundo dos recursos da tecnologia da informação, a qual forneceu base material para a sua expansão em toda a estrutura social (CASTELLS, 2005).

\subsection{A EXCLUSÃO DIGITAL NO BRASIL}

Neste tópico, a partir das reflexões realizadas anteriormente acerca do surgimento da TICs e da sociedade em rede, busca-se trazer a questão da exclusão digital no Brasil a fim de refletir a respeito da denúncia comum ao se tratar das potencialidades atreladas ao uso das tecnologias da informação e comunicação em matéria de democracia e cidadania.

Há que se pontuar, inicialmente, do ponto de vista terminológico, a existência de diferentes rótulos para denominar o acesso e o uso desigual dos recursos digitais, dentre os quais, os termos mais comuns são exclusão digital, apartheid digital, brecha digital, fissura digital, fratura digital, ou, de forma mais regular na literatura anglo-saxã, digital divide, ou, no português, divisão digital (MARQUES, 2014). 
Para Elisabeth Gomes (2002), o Brasil se equivocou quanto ao caminho para chegar à era digital, pois priorizou os fabricantes de computadores, o que ressaltou a exclusão social no País.

$\mathrm{Na}$ verdade, quanto à questão do atraso no desenvolvimento digital e social no contexto brasileiro, convém mencionar a exposição de Jessé Souza, em sua conhecida obra "A elite do atraso" (2017), ao pontuar que o capital ocupou papel determinístico na nossa economia e conduziu historicamente, mesmo que indiretamente, as discussões sociais e políticas do País, com preferência aos interesses da elite econômica.

Nesse sentido, a exclusão ou desigualdade digital se soma à já existente desigualdade e exclusão social, em uma interação mais complexa, que deixa a impressão de distanciar a promessa da Era da Informação, em uma realidade obscura para muitos em todo o mundo (CASTELLS, 2015).

No caso brasileiro, de forma mais ampla que em outros países, a exclusão digital está mais marcadamente atrelada à discussão da exclusão social, uma vez que deriva das desigualdades socioeconômicas e culturais, tais como analfabetismo, desemprego, baixa renda e educação, em uma relação mútua de causa e consequência. Os fatores que levam à exclusão social deságuam na exclusão digital e esta contribui para o aprofundamento daquela (ALMEIDA et al., 2005).

Para Randolph e Lima (2012), a temática da exclusão digital envolve a reflexão acerca da difusão e do uso de tecnologias de manejo e transmissão de informação, que permitem uma comunicação mútua (interativa) entre seus diferentes usuários.

A exclusão digital, em resumo, pode ser entendida como "[...] o acesso desigual dos recursos relacionados à tecnologia de informação e comunicação entre ou dentro dos continentes, países, região ou até mesmo bairros" (ARAUJO, 2015, p. 16).

A respeito disso, segundo levantamento realizado pelo Instituto Brasileiro de Geografia e Estatística - IBGE (2020), durante a Pesquisa Nacional por Amostra de Domicílios - PNAD Contínua, em 2017, a Internet era utilizada em 74,9\% dos domicílios do País e esse percentual subiu para $79,1 \%$ em 2018.

Ainda, ficou constatado que o principal meio de acesso à internet no domicílio era o telefone móvel celular, que, em 2018 , alcançou $99,2 \%$ dos domicílios onde havia a utilização da internet, sendo que o microcomputador se encontrava em segundo lugar, uma vez que era usado para acessar a Internet por $48,1 \%$ dos domicílios onde havia a utilização dessa rede.

Em diferente levantamento realizado pelo Comitê Gestor da Internet no Brasil - CGI (2019), durante a pesquisa TIC Domicílios, constatou-se, em 2018, que 67\% dos domicílios brasileiros possuíam acesso à internet, sendo $70 \%$ correspondentes à área urbana e $30 \%$ à área rural, bem como se concentrando o maior percentual de acesso nas regiões Sudeste (73\%) e Sul (69\%).

Castells (2015) tratou de discutir essa questão e argumenta que não causa surpresa quando, ao se proclamar o potencial da internet como um meio de liberdade, produtividade e comunicação, observa-se a crítica quanto à digital divide causada pela desigualdade a ela associada, uma vez que a centralidade da internet em muitas áreas da atividade social, eco- 
nômica e política equivale à marginalidade para aqueles que não têm acesso a ela, ou têm apenas um acesso limitado, ou não sabem usá-la de forma eficaz.

A desigualdade social nas práticas democráticas, por certo, é questão comum nas discussões em teoria política, seja sob o olhar da participação, seja pelo prisma da literatura de cunho liberal. Contudo, além das questões sociais e da desigualdade nas oportunidades atreladas à ausência ou ao pouco envolvimento político dos cidadãos, há questões pessoais envolvidas, relacionadas à personalidade, às experiências diversas, às preferências e motivações e a outros fatores que afastam a ideia de que a igualdade perfeita seja um objetivo político plausível (MARQUES, 2014).

Pois bem, de forma análoga à desigualdade ou à exclusão social, busca-se refletir a respeito da exclusão digital, não somente sob o prisma das características pessoais de acesso, mas também a respeito da falta de oportunidades básicas que possibilitem o desfrute dos serviços oferecidos pelo Estado ou a tomada de espaço nas consultas regularmente oferecidas em diferentes níveis governamentais (MARQUES, 2014).

Roberto, Fidalgo e Buckingham (2015, p. 51), em suas conclusões de pesquisa realizada com estudantes universitários em Portugal, afirmam que,

No que concerne aos grupos sociais mais afetados pela infoexclusão, os nativos digitais evidenciam, em geral, facilidade em identificar os jovens e os idosos como sendo os que têm maior e menor acesso, respectivamente. Referem, ainda, a importância do estatuto socioeconômico e da escolaridade enquanto fatores determinantes para garantir a facilidade de acesso às TIC. Considerando a identificação destes grupos e os fatores potenciadores da infoexclusão, os nativos digitais evidenciam uma visão estereotipada e redutora do idoso que sustenta a desvalorização social da velhice.

É aqui que se encontra uma das reflexões deste artigo, o qual pretende discutir se a utilização das tecnologias torna a sociedade mais eficiente, ou com mais oportunidades de participação na tomada de decisões públicas, ou, ainda, se aumenta a exclusão e a desigualdade social nela já existente em suas várias acepções.

Importante frisar, antes de tudo, que se considera insuficiente analisar a digital divide tão somente pela estatística considerada na posse ou no acesso aos meios de comunicação, na medida em que, embora necessários, existem outros elementos nesse processo, tais como as peculiaridades individuais de quem acessa ou as associadas à posição geográfica (MARQUES, 2014).

Sobre esse ponto, relevante é o diagnóstico realizado por Pippa Norris (2001), a qual catalogou o problema em três faces: sendo a primeira referente à divisão global e às diferenças de acesso à tecnologia digital e à infraestrutura das redes telemáticas nos diversos países; a segunda, no tocante à divisão social e às disparidades internas de uma sociedade, catalogando quanto ao acesso aos equipamentos e às habilidades necessárias para o manuseio das tecnologias da informação e comunicação; e, por último, destaca-se a existência de uma exclusão digital na democracia (democratic digital divide), cujo foco está no emprego de recursos digitais e na mobilização política.

Ainda sobre a temática da exclusão digital, importa apresentar os aspectos inventariados que envolvem a digital divide e colaboram para o seu entendimento e proposição de soluções. 
Consoante Marques (2014, p. 101-102), esses aspectos podem ser classificados em três categorias:

a) aspectos técnicos:

- velocidade de conexão,

- hardware e software das máquinas, que permitem experiências distintas aos usuários,

- estrutura de backbones e backhauls em cada localidade (artifícios técnicos que permitem a conexão física entre redes de computadores e, logo, possibilitam a troca de dados),

- números de IP;

b) aspectos individuais e sociais:

- idade,

- gênero,

- renda (para adquirir dispositivos de comunicação, contratar serviços de conexão à Internet ou obter acesso a informações pagas),

- grau de escolaridade,

- capacidade de uso da língua (Inglês como idioma universal),

- etnia,

- diferenças culturais (entre nativos e imigrantes, por exemplo),

- habilidades para operar os recursos de comunicação digital,

- motivação para empregar os dispositivos,

- pressão externa para se utilizar as redes de comunicação digital (trabalho, família ou escola),

- autonomia para o consumo e para a produção de conteúdos,

- qualidade da informação a que se tem acesso,

- estágio da vida em que se teve acesso às tecnologias digitais de comunicação (ter acesso à Internet quando criança ou apenas depois de adulto),

- tempo diário de conexão,

- aspectos comportamentais de cada indivíduo (grau de inibição, por exemplo);

c) aspectos geográficos:

- países (alega-se maior capacidade de influência a depender do lugar de origem do usuário),

- regiões de uma mesma cidade ou estado (áreas urbanas ou áreas rurais),

- local costumeiro no qual o usuário acessa a Internet (casa, trabalho, lan house).

Sorj e Guedes (2005) escrevem que o enfretamento do tema da exclusão digital deve ocorrer a partir de uma visão sistêmica da realidade brasileira, de forma que, ao lado da promoção de políticas de universalização do acesso à internet, procure-se promover a universalização de outros bens sociais, tais como a educação, o saneamento, a segurança, a saúde e os serviços jurídicos. 
No mesmo sentido, Adriane Matos de Araujo (2016) pontua que a educação constitui um papel fundamental no combate à exclusão digital e, por isso, é preciso que se reflita acerca da alfabetização e do letramento digital como mecanismos de apropriação das tecnologias digitais e, de forma mais ampla, da educação digital, considerando a construção social coletiva vinculada às culturas digitais e às identidades sociais atuantes na inteligência coletiva.

Diante disso, percebe-se que os aspectos que envolvem a exclusão digital vão além do mero acesso à internet ou aos tradicionais mecanismos eletrônicos, tais como computador ou celular, visto que abarcam diversos fatores, como de ordem técnica, individual ou social e geográfica, o que pode se consubstanciar em óbice a ampliação de seu uso instrumental na participação democrática.

\section{INOVAÇÓES TECNOLÓGICAS APLICADAS À CIDADANIA PARTICIPATIVA}

\subsection{A CIDADANIA PARTICIPATIVA: APONTAMENTOS TEÓRICOS E CONCEITUAIS}

Inicialmente, antes do desenvolvimento teórico referente à aplicação das TICs à cidadania participativa, faz-se necessário contextualizar o que significa o termo cidadania. Tal objetivo não é algo fácil, tendo em vista que a cidadania não possui um conceito uniforme.

Para Gohn (2005, p. 18), "[...] dentre os conceitos utilizados pelos intelectuais, políticos, administradores públicos, e pela mídia, cidadania é, provavelmente, o que tem tido o maior uso (e abuso) de significados e ressignificados".

Etimologicamente, advém do latim e possuía o sentido daquele que habitava a cidade, tendo correlação ao conceito de povo (GORCZEVSKI; MARTIN, 2011). Cabe registrar que ao mesmo tempo que tem um sentido de inclusão/pertencimento ela também traz consigo a exclusão daqueles(as) que não são seus(uas) detentores(as) (VIEIRA, 2013).

Ela se manifesta de várias formas e recebe as mais diversas classificações: cidadania representativa, cidadania semidireta, cidadania eleitoral, cidadania participativa, cidadania eletrônica, cidadania liberal, cidadania social, cidadania republicana, etc.

No que concerne à cidadania participativa, a Constituição da República Federativa do Brasil de 1988 representou um marco no seu reconhecimento no Brasil, uma vez que, além dos instrumentos clássicos da democracia representativa, restou enfatizada a necessidade da participação dos cidadãos na qualidade de detentores da soberania popular, o que pode ser trazido também como um novo paradigma que pressupõe a existência de uma cidadania não meramente formal, mas efetivamente participativa (VIEIRA, 2013).

Consoante escreve Vieira (2013), a Constituição da República Federativa do Brasil de 1988 representou um verdadeiro divisor de águas no que diz respeito ao reconhecimento de direito e à inclusão da cidadania participativa ao lado da representativa em um texto cons- 
titucional nacional, uma vez que, antes dela, em termos de cidadania, não verificava significativos espaços de participação, bem como havia limitações para o exercício da democracia representativa.

Mas o que, de fato, vem a ser a cidadania participativa? Em que espécie de democracia ela melhor se amolda?

Pode-se dizer que a cidadania efetivamente participativa deve abarcar espaços nos quais os cidadãos podem colaborar para a tomada de decisões que envolvam os rumos da sociedade, por meio do diálogo, da opinião, da consulta, do voto e da crítica.

Nessa linha de raciocínio, o texto constitucional brasileiro tratou de consagrar espaços participativos, tais como audiências públicas, planejamento e orçamento públicos participativos, os fóruns do Estado da Cidade, bem como as Conferências e os Conselhos de Direitos (VIEIRA, 2013).

Tal cenário de participação se verifica pela lógica democrática da bem denominada democracia participativa, a qual se entrelaça com o significado e a existência da cidadania participativa aqui trabalhada.

Vislumbra-se uma crise do paradigma democrático liberal pautada na ideia de representação da cidadania e no monismo jurídico. Uma crise que perpassa todas as suas instituições e que não pode ser resolvida apenas com os instrumentos da modernidade burguesa, construída a partir de suas mitologias e abstrações as quais retiraram a complexidade da sociedade, restando a simplicidade que o modelo capitalista necessidade para o seu desenvolvimento e reprodução (CAPELLA, 2002; GROSSI, 2007; PILATI, 2012; VIEIRA, 2013).

Assim, a democracia participativa parece ocupar maior atenção, na medida em que tenta resgatar a noção do povo como verdadeira detentora da soberania e protagonista do interesse público.

A democracia participativa tem experimentado buscar uma resposta para as promessas não cumpridas pela democracia representativa, consistente na restituição "[...] aos sujeitos uma iniciativa política e uma influência no processo de decisão que hoje parecem comprometidos pelo formalismo do sistema representativo e pelo elitismo dos partidos" (COSTA, 2012, p. 300).

Segundo Pateman (1992, p. 60-61), a democracia participativa

[...] é construída em torno da afirmação central de que os indivíduos e suas instituições não podem ser considerados isoladamente. A existência de instituições representativas a nível nacional não basta para a democracia; pois o máximo de participação de todas as pessoas, a socialização ou 'treinamento social', precisa ocorrer em outras esferas, de modo que as atitudes e qualidades psicológicas necessárias possam se desenvolver. [...] A principal função da participação na teoria da democracia participativa é, portanto, educativa; educativa no mais amplo sentido da palavra, tanto no aspecto psicológico quanto no de aquisição de práticas de habilidades e procedimentos democráticos. [...] A participação promove e desenvolve as próprias qualidades que the são necessárias; quanto mais os indivíduos participam, melhor capacitados eles se tornam para fazê-lo.

Portanto, a democracia participava não tem por objetivo a substituição da democracia representativa por completo. Inobstante, a democracia representativa tem rejeitado a legi- 
timidade de democracia participativa, o que tem ocasionado certo conflito, o qual só terá solução na medida em que essa recusa for deixada de lado para ser absorvida como forma de complementariedade entre as duas formas de democracia, de modo a contribuir para o aprofundamento de ambas (SANTOS, 2002).

Nesse contexto de complementariedade, no Brasil, a partir da Constituição de 1988, consagrou-se o paradigma da necessidade de participação da sociedade na qualidade de detentora da soberania popular, assim transcendendo a tradicional democracia representativa exercida por meio dos partidos políticos, sendo estabelecidos mecanismos de exercício semidiretos do poder: iniciativa popular, plebiscito e referendo. Contudo, apesar de sua importância, possuem seus exercícios limitados dentro da ótica formalista e monista do sistema jurídico (VIEIRA, 2013).

Embora tenham ocorrido tais limites formais aos mecanismos de iniciativa popular, ao plebiscito e ao referendo, também foram reconhecidos outros espaços de cidadania, tais como a participação da comunidade na área da saúde e em outras área das políticas públicas (conselhos de direitos ou conselhos gestores de políticas públicas), o direito de reunião e associação, o direito à informação em órgãos públicos, o direito de petição e obtenção de certidões em órgãos públicos para a defesa de direitos, a ação popular, a iniciativa popular municipal, a realização de audiências públicas no Congresso Nacional com a participação da sociedade, a possibilidade de um cidadão apresentar denúncias perante o Tribunal de Contas, o recebimento de reclamações da sociedade contra órgãos do Poder Judiciário perante o Conselho de Justiça, o recebimento de reclamações da sociedade contra órgãos do Ministério Público perante o Conselho Nacional do Ministério Público (VIEIRA, 2013).

Dentre os espaços de cidadania, destaca-se também o controle social (da sociedade em relação ao Estado), o qual se diferencia da participação social em razão da forma como interagem as decisões em matéria pública. 0 controle se constitui no mecanismo que confere a possibilidade de as decisões serem substituídas, enquanto a participação consubstancia-se na existência de canais, instituições de interação entre o governo e a sociedade, com a presença de sujeitos coletivos nos processos de tomada de decisão nas escolhas públicas (BITENCOURT, 2019).

E é no espaço do controle social, em consonância com o exercício da cidadania participativa, que o uso das TICs e da cidadania eletrônica se configura em um elemento necessário para a ampliação da participação e da fiscalização do bem público.

\subsection{O PROBLEMA DA DIGITAL DIVIDE E A BUSCA PELA CIDADANIA EFETIVAMENTE PARTICIPATIVA}

A democracia eletrônica ou digital pode ser entendida "[...] como o conjunto dos recursos, ferramentas, projetos, experimentos, experiências e iniciativas em que se usam tecnologias para produzir mais democracia e melhores democracias" (GOMES, 2018, p. 1832).

Nessa linha, a noção de cidadania também se entende a partir do incremento tecnológico nas suas mais variadas formas de manifestação. Esse modelo é referido por Perez Luño (2004) como um processo menos formal da cidadania, o que ele denomina cibercidadania ou 
cidadania.com. Pode-se dizer, então, que a discussão da participação popular digital ganha um elemento adicional quanto às formas tradicionais de participação: o digital.

Desse modo, além das dificuldades tradicionais para a participação popular, as quais envolvem a capacidade do cidadão para apresentar, de forma persuasiva, os próprios argumentos ou reivindicações, deve ser avaliado, no contexto digital, se os cidadãos possuem iguais condições de recursos para o acesso aos dados e aos argumentos em discussão (FERREIRA, 2011).

Segundo bem menciona Araujo (2015), o debate acerca da exclusão digital, quando relacionado à temática da cidadania, deve considerar o acesso e o uso crítico da informação, sendo que o acesso está atrelado à infraestrutura tecnológica para a conexão à internet e à disponibilidade de informação, enquanto o uso crítico envolve a forma como os indivíduos utilizam a internet.

Importante destacar, de igual forma, algumas críticas elencadas por Wilson Gomes (2018) oriundas de trabalhos científicos publicados a respeito da chegada da democracia digital ou eletrônica, as quais serão objeto de reflexão a seguir.

A primeira diz que a democracia digital não poderá, através do uso das tecnologias da informação e comunicação, resolver os problemas da democracia (GOMES, 2018).

Tal crítica não parece ter muito sentido, uma vez que dados governamentais íntegros, atualizados, abundantes e à disposição dos cidadãos são fundamentais para a democracia, para melhorar a vida das pessoas e até para o progresso da sociedade. Ainda, a democracia digital visa agregar e não substituir, sendo que nada é automático na democracia, nem a existência dos melhores meios tecnológicos à disposição (GOMES, 2018).

A segunda afirma que a democracia que emergiria da democracia eletrônica seria uma versão rebaixada e pobre, consistindo-se em mero dispositivo de registrar preferência (GOMES, 2018).

Mais uma vez, tal crítica é rasa e não compreende a totalidade da democracia digital, uma vez que mistura uma função mínima que determinada tecnologia pode prestar e um juízo geral sobre a democracia como resultante apenas do cumprimento dessa função (GOMES, 2018).

Nessa linha, Lévy (2003) ressalta que a utilização da Internet, aliada à democracia, constitui um dos fundamentos da ciberdemocracia, sendo que, de forma diversa dos meios de comunicação da democracia midiática da segunda metade do século XX, tais como imprensa, rádio e televisão, permite-se a todos os cidadãos navegadores da rede mundial de computadores a possibilidade de expressarem suas opiniões e intenções sem terem de passar pelo poder do jornalista, de forma a alargar, diversificar e até complicar a esfera pública, ou seja, conferindo maior liberdade à palavra.

Uma terceira crítica tenta sustentar que a democracia eletrônica pode produzir assimetrias antidemocráticas, uma vez que produziria maior exclusão social diante da exclusão tecnológica (GOMES, 2018).

De fato, o desenvolvimento de recursos tecnológicos voltados para a democracia digital sem observar as questões de inclusão digital pode aprofundar ainda mais a exclusão social. Contudo, se consideradas as questões de inclusão digital, tem-se que a inclusividade digital 
pode, na verdade, reduzir a exclusão social, contribuindo para o processo de aprimoramento das formas de exercício da democracia e da cidadania.

Assim, a tecnologia associada à cidadania participativa, naquilo que se pode denominar de cidadania participativa digital, ao lado dos mecanismos tradicionais, quando pensada em conjunto com os fatores de inclusão digital, confere ampliação e não diminuição dos espaços para a participação e o exercício da cidadania.

Por fim, uma quarta crítica tenta fazer crer que a democracia digital não é capaz de produzir condições melhores de participação civil e deliberação pública, então ela não pode ajudar a melhorar a democracia (GOMES, 2018).

Nessa linha, Ferreira (2011) pontua que se faz necessário diferenciar as desigualdades de participação offline e online, uma vez que se deve verificar se caso superadas as barreiras de acesso à participação online haverá impacto nos fatores de desigualdade offline, posto que estudos recentes têm demonstrado que os principais obstáculos à realização de deliberações públicas decorrem da apatia política e não de obstáculos à possibilidade de expressão ou de comunicação.

Entretanto, cabe registrar que os obstáculos para o exercício da cidadania podem ampliar essa apatia política ao dificultarem e indiretamente desestimularem a participação democrática.

Outrossim, a respeito da relação entre o uso da Internet e o exercício da cidadania, Lévy (2003) menciona que aqueles que desfrutam dessa tecnologia tendem a votar mais, possuem mais informação, sentem em si uma melhor capacidade de ação sobre o mundo e têm mais confiança no processo democrático.

A democracia digital não consiste apenas em gerar mais participação civil e deliberação pública, mas também em fornecer informações que promovam a transparência, a abertura e a responsabilização das agências governamentais em nível nacional e internacional, bem como em fortalecer os canais de comunicação interativa entre cidadão e instituições intermediárias (GOMES, 2018).

Sorj e Guedes (2005) ressaltam a importância que as escolas assumem enquanto instrumentos para socializar as novas gerações para o uso da Internet. Os autores apontam que se deve buscar implementar políticas de incentivo ao uso de softwares e de equipamentos eletrônicos por parte de alunos(as) a fim de capacitá-los(as) para o conhecimento de programas básicos e de motivá-los(as) para o uso desses diferentes recursos tecnológicos.

Nesse sentido, com o rompimento gradual desses obstáculos de acesso e uso das novas tecnologias, pode-se, no contexto da democracia digital, possibilitar que seja construído um espaço maior de diálogo, interação e participação do cidadão nas decisões políticas, acabando por se consubstanciar em um instrumento que pode, de forma complementar, contribuir para uma maior instrumentalização e o alcance da democracia participativa (PICANYOL, 2008). 


\section{CONCLUSÃO}

O presente trabalho buscou refletir acerca do impasse inerente à exclusão digital ou digital divide e seu impacto para a cidadania participativa no contexto da sociedade em rede.

Como visto, as transformações advindas da tecnologia e, em especial, da invenção da internet revolucionaram a forma de viver em sociedade, agora denominada sociedade em rede. A sociedade, antes desconectada e isolada, passou a viver de forma global e interconectada por sistemas de redes.

Esse novo formato de sociedade em rede, embora entrelace, direta ou indiretamente, todas as pessoas, não trouxe consigo a resolução da exclusão social (o que não teria o condão de fazê-lo, tendo em vista a complexidade de fatores que envolvem tal exclusão), mas sim mais lucidez à outra forma de exclusão, a digital, o que deve ser enfrentado pelo Estado e pela sociedade.

A exclusão social possui raízes mais profundas, que impactam a vida das pessoas aos bens e serviços públicos, inclusive ao acesso ao direito fundamental à informação e ao conhecimento.

A digital divide (exclusão digital), oriunda da vida digital, que também é atingida pela exclusão social, com destaque ao Brasil, um país marcado fortemente pela desigualdade social, possui características próprias que foram detalhadas no desenvolvimento deste estudo.

Superar a exclusão digital é fundamental para a ampliação da utilização da cidadania digital ou cibercidadania como instrumento para a ampliação e o fortalecimento da participação política, em especial no âmbito da cidadania participativa.

Essa cidadania participativa, insculpida no corpo do texto constitucional de 1988, não refuta a importância da cidadania representada e dos partidos, mas coabita com ela com o intuito de ampliar o exercício da participação democrática na esteira do preconizado pelo Estado Social e Democrático de Direito.

Portanto, a cidadania efetivamente participativa deve abarcar espaços nos quais os cidadãos possam colaborar para a tomada de decisões que envolvam os rumos da sociedade, por meio do diálogo, da opinião, da consulta, do voto e da crítica.

Ademais, a construção teórica desta pesquisa demonstrou que os aspectos que envolvem a exclusão digital vão além do mero acesso à internet ou aos tradicionais mecanismos eletrônicos, tais como computador ou celular, uma vez que abarcam diversos fatores, como os de ordem técnica, individual ou social e geográfica.

Nesse sentido, cabe ressaltar o papel da educação nesse processo a partir das escolas, mas não somente por meio delas, tendo em vista a necessidade de pensar na inclusão daqueles(as) que já não estão no ambiente escolar ou que pouco contato tiveram com esse ambiente, os(as) quais também merecem atenção quanto à temática da exclusão digital, uma vez possuem papel socializante para as novas gerações na internet. Portanto, um desafio que exsurge é a necessidade de criarem-se condições para a implantação da educação digital nas escolas brasileiras (o que, no caso das escolas públicas, pode contribuir para a 
diminuição da exclusão social), voltadas tanto para o mercado de trabalho e econômico, quanto para o exercício da cidadania.

Destarte, para que ocorra o acesso à informação e ao conhecimento por meio do uso das TICs e, por consequência, da disseminação da cidadania participativa digital, necessária se faz a ampliação/criação de políticas públicas de combate às desigualdades sociais e a criação de instrumentos que possibilitem incluir aqueles(as) excluídos(as) digitalmente, inclusive por seus aspectos culturais, étnicos, geracionais, técnicos ou geográficos.

É preciso investimento público no desenvolvimento de soluções voltadas para a cidadania, por meio das técnicas de engenharia de software e da utilização das tecnologias de informação e comunicação.

No âmbito da participação popular, o desenvolvimento de instrumentos eletrônicos, de cunho não só informativo, mas com efetiva interação cidadã, quanto às discussões realizadas no Poder Legislativo, mediante acesso pela internet, poderiam contribuir para a redução da exclusão digital e permitir uma maior interação da sociedade no processo legislativo.

Em matéria de transparência pública, o aperfeiçoamento dos portais eletrônicos a fim de ampliar as informações e os documentos disponíveis para além do que a legislação propõe, em uma concepção de Administração Pública digital, também tem condão para contribuir para a melhora da cidadania, ao menos em termos de acesso, quanto à exclusão digital.

Por fim, no tocante à cidadania participativa no âmbito das políticas públicas, o desenvolvimento de canais digitais interativos para os conselhos de direitos, em especial os municipais, também representaria uma medida digitalmente inclusiva, que daria mais visibilidade e fortalecimento a esses espaços da democracia participativa, amparados no paradigma do Estado Social e Democrático de Direito, que foi reconhecido no texto da Constituição da República Federativa do Brasil de 1988.

A verdade é que não existe somente uma solução para a eliminação da exclusão digital, tal como a exclusão social, mas sim diversas pontes que podem levar ao cenário mais inclusivo possível, sendo que toda medida de inclusão digital contribuirá para uma melhora social e vice-versa.

Nesse contexto, cabe uma última reflexão: não se pode culpar os recursos tecnológicos como causadores da desigualdade social, pois isso é algo que não se sustenta. A problemática associada à exclusão social é algo mais profundo, enraizado a elementos históricos de um processo político e econômico excludente, que marcaram e continuam marcando profundamente a sociedade brasileira e os demais países da América Latina.

\section{REFERÊNCIAS}

ALMEIDA, Lília Bilati de et al. O retrato da exclusão digital na sociedade brasileira. JISTEM J. Inf. Syst. Technol. Manag., [Online], São Paulo, v. 2, n. 1, p. 55-67, 2005. Available from: http://www.scielo.br/scielo.php?script=sci_ arttext\&pid=S1807-17752005000100005\&lng=en\&nrm=iso. Access on: 26 aug. 2020. 
ARAUJO, Lucimar Goulart da Costa. O projeto de inclusão digital no Brasil: avanços e lacunas. 2015. Dissertação (Mestrado em Estudos Populacionais e Pesquisas Sociais) - Escola Nacional de Ciências Estatísticas, Rio de Janeiro, 2015.

BITENCOURT, Caroline Müller. Acesso à informação para o exercício do controle social: desafios à construção da cultura da transparência no Brasil e diretrizes operacionais e legais para os portais no âmbito municipal. Relatório de Pesquisa Pós-Doutoral. Curitiba: PPGD-PUCPR, 2019.

CAPELLA, Juan Ramón. Fruto proibido: uma aproximação histórico-teórica ao estudo do Direito e do Estado. Tradução de Gresiela Nunes Rosa e Lédio Rosa de Andrade. Porto Alegre: Livraria do Advogado, 2002.

CASTELLS, Manuel. A Sociedade em rede. 8. ed. rev. e amp. São Paulo: Paz e Terra, 2005.

CASTELLS, Manuel. A Galáxia da Internet: reflexões sobre a internet, os negócios e a sociedade [recurso eletrônico]. Rio de Janeiro: Jorge Zahar Ed., 2015.

CÔMITE GESTOR DA INTERNET NO BRASIL - CGI. Pesquisa sobre o uso das tecnologias de informação e comunicação dos domicílios brasileiros: TIC domicílios 2018 [livro eletrônico]. São Paulo: Núcleo de Informação e Coordenação do Ponto BR, 2019.

COSTA, Pietro. Poucos, muitos, todos: lições da história da democracia. Curitiba: Editora UFPR, 2012.

FERREIRA, Gil Baptista. Democracia digital e participação política: o acesso e a igualdade na deliberação online. Media \& Jornalismo, Instituto Politécnico de Coimbra, n. 18, v. 10, n. 1, pp. 46-61, 2011.

GOHN, Maria da Glória. O protagonismo da sociedade civil: movimentos sociais, ONGs e redes solidárias. São Paulo: Cortez, 2005.

GOMES, Elisabeth. Exclusão digital: um problema tecnológico ou social? Trabalho e Sociedade, Rio de Janeiro, ano 2, n. especial, dez. 2002. 8 p. Disponível em: http://www.radio.faced.ufba.br/twiki/pub/GEC/RefID/Elisabeth_ Gomes_ED.pdf. Acesso em: 26 ago. 2020.

GOMES, Wilson. A democracia no mundo digital: história, problemas e temas. São Paulo: Edições Sesc, 2018.

GORCZEVSKI, Clovis; MARTíN, Nuria Belloso. A necessária revisão do conceito de cidadania: movimentos sociais e novos protagonistas na esfera pública democrática [recurso eletrônico]. Santa Cruz do Sul: Edunisc, 2011. Disponível em: www.unisc.br/edunisc. Acesso em: 20 jul. 2019.

GROSSI, Paolo. Mitologias jurídicas da modernidade. Tradução de Arno Dal Ri Jr. 2. ed., rev. e atual. Florianópolis: Fundação Boiteux, 2007.

INSTITUTO BRASILEIRO DE GEOGRAFIA E ESTATÍSTICA - IBGE. Diretoria de Pesquisas, Coordenação de Trabalho e Rendimento. Pesquisa Nacional por Amostra de Domicílios Contínua 2017-2018. Brasília, DF: IBGE, 2020.

KUHN, Thomas S. A estrutura das revoluções científicas. Tradução de Beatriz Vianna Boeira e Nelson Boeira. 5. ed. São Paulo: Perspectiva, 1997.

LÉVY, Pierre. Ciberdemocracia. 1. ed. Porto Alegre: Instituto Piaget, 2003.

MARQUES, Francisco Paulo Jamil Almeida. Democracia on-line e o problema da exclusão digital. Intexto, Porto Alegre, n. 30, p. 93-113, jul. 2014.

MORIN, Edgar. O método 4: as ideais: habitat, vida e costumes. Tradução de Juremir Machado da Silva. 5. ed. Porto Alegre: Sulina, 2011.

NORRIS, Pippa. Digital Divide: Civic Engagement, Information Poverty, and the Internet Worldwide. New York (EUA): Cambridge University Press, 2001.

PATEMAN, Carole. Participação e teoria democrática. Tradução de Luiz Paulo Rouanet. Rio de Janeiro: Paz e Terra, 1992.

PÉREZ-LUNO, Antonio Henrique. Ciberciudadaní@ociudadanía.com? Barcelona: Gedisa, 2004.

PICANYOL, Jordi Sanches i. La democracia electrónica. Barcelona: UOC, 2008.

PILATI, José Isaac. A propriedade e função social na pós-modernidade. 2. ed. Rio de Janeiro: Lumen Juris, 2012. 
RANDOLPH, Rainer; LIMA, Mário Hélio Trindade de. Novas formas de exclusão social? Reflexões sobre o digital divide. Cadernos Metrópole, [S.I.], n. 4, p. 93-117, maio 2012. ISSN 2236-9996. Disponível em: http://revistas. pucsp.br/metropole/article/view/9303. Acesso em: 26 ago. 2020.

ROBERTO, Magda Sofia; FIDALGO, António; BUCKINGHAM, David. De que falamos quando falamos de infoexclusão e literacia digital? Perspectivas dos nativos digitais. OBS*, Lisboa, v. 9, n. 1, p. 43-54, jan. 2015. Disponível em: http://www.scielo.mec.pt/scielo.php?script=sci_arttext\&pid=S1646-59542015000100003\&lng=pt\&nrm=iso. Acesso em: 30 abr. 2020.

ROVER, Aires José. Governo eletrônico e inclusão digital. Florianópolis: Fundação Boiteux, 2009.

SANTOS, Boaventura de Sousa. Democratizar a democracia: os caminhos da democracia participativa. Rio de Janeiro: Civilização Brasileira, 2002.

SORJ, Bernardo; GUEDES, Luís Eduardo. Exclusão digital: problemas conceituais, evidências empíricas e políticas públicas. Novos estud. - CEBRAP, São Paulo, n. 72, p. 101-117, jul. 2005. Disponível em: http://www.scielo.br/ scielo.php?script=sci_arttext\&pid=S0101-33002005000200006\&lng=en\&nrm=iso. Acesso em: 26 ago. 2020.

SOUZA, Jessé. A elite do atraso: da escravidão à Lava Jato. Rio de Janeiro: Leya, 2017.

VIEIRA, Reginaldo de Souza. A cidadania na república federativa: pressupostos para a articulação de um novo paradigma jurídico e político para os conselhos de saúde. 2013. 540 f. Tese (Doutorado em Direito) - Universidade Federal de Santa Catarina, Florianópolis, 2013.

Recebido/Received: 29.06.2020.

Aprovado/Approved: 26.12.2020. 